\title{
Utilizing the Expectancy Value Theory to Predict Lecturer Motivation to Apply Culturally Responsive Pedagogies in Universities in Botswana
}

\author{
Norman Rudhumbu and Elize du Plessis \\ University of South Africa, College of Education, Pretoria, South Africa \\ https://orcid.org/0000-0002-2536-5511 \\ https://orcid.org/0000-0003-4299-4632
}

\begin{abstract}
The expectancy value theory (EVT) has been used in many studies to predict the motivation processes of individuals with regard to how they think and act in particular ways. Critical to how individuals think and act are the three elements of the EVT, namely the expectancy cognition (expectancy), instrumentality cognition (instrumentality) and valence. This study therefore seeks to establish whether the EVT could be used to predict and explain the motivation of lecturers to apply culturally responsive pedagogies (CRPs) in the teaching of culturally heterogeneous classes in universities in Botswana. Using a sample of 291 lecturers from three selected universities, the study employed a structured questionnaire for data collection. Confirmatory factor analysis (CFA) was used for data purification. Structural equation modelling (SEM) using AMOS version 22 was used for data analysis. The study established that the expectancy $(\beta=.419 ; \mathrm{p}<.001)$ and instrumentality $(\beta$ $=.315 ; \mathrm{p}<.001)$ cognitions of lecturers as well as the valence $(\beta=.268 ; \mathrm{p}$ $<.001$ ) had a significant influence on the motivation of lecturers to apply CRPs in the teaching of culturally heterogeneous classes in universities. These results also showed significant relationships between expectancy cognition and valence $(\beta=.316 ; p<.001)$ and also between instrumentality cognition and valence $(\beta=.301 ; \mathrm{p}<.001)$. These results therefore demonstrate that the EVT could be used to predict the motivation of lecturers in universities to apply CRPs in their teaching of culturally diverse university students.
\end{abstract}

Keywords: cultural diversity; culturally responsive pedagogies; expectancy cognition; expectancy value theory; instrumentality cognition

\section{Introduction}

Various studies have alluded to the critical role of culturally responsive pedagogies and multicultural competences in today's culturally heterogeneous university students (Maasum et al., 2014; Brown et al., 2018; Dorrington \& Guy, 
2018). The concept of culture in particular has been a subject of contestation in terms of how it influences the behaviour of individuals regarding how they think and act (Brown \& Crippen, 2017; Brown, 2014). As a "dynamic system of social values, cognitive codes, behavioural standards, worldviews, and beliefs used to give order and meaning to our ways of life as well as that of others" (Gay, 2018, p.8), culture is viewed as critical for the effective teaching of culturally diverse students in universities (Nagasawa, 2020). A study by Diller and Mouler (2005) found that for lecturers to teach multicultural groups of students effectively, they need to have multicultural competences; that is, an awareness of the knowledge, skills and personal attributes needed to teach in a culturally diverse classroom environment. This is in line with results of separate studies by Howe et al. (2021) and Wrench and Garrett (2020) which found that curricula and teaching strategies that fail to utilize the cultural resources of students fail to provide critical experiences for students to benefit from teaching and learning processes. This also means that lecturers need to have a clear understanding of the different cultures in their classrooms other than their own cultures so that they are able to use teaching approaches that acknowledge and respond to these cultural differences. The teaching strategies that are employed to teach culturally heterogeneous students are referred to as culturally responsive pedagogies (Brown et al., 2018).

Various studies and the extant literature allude to the fact that the use of CRPs in the teaching of university students who are culturally diverse is still a new phenomenon within the collection of pedagogical strategies used in universities (Brown et al., 2018; Dorrington \& Guy, 2018). Therefore research to establish whether lecturers in universities apply such a pedagogical approach is critical, especially considering how diverse the university student body has become globally. This study therefore wishes to establish whether the EVT could be used to predict and explain lecturer motivation to apply CRPs in the teaching of culturally heterogeneous university students in Botswana. To achieve this aim, the study was guided by the following research questions:

- What are the dimensions of the EVT that can be used to predict and explain lecturer motivation to apply CRPs in universities?

- To what extent does the expectancy cognition of lecturers influence their motivation to apply CRPs in the teaching of students of diverse cultural backgrounds in universities?

- How significantly does valence influence lecturer motivation to apply CRPs in the teaching of students of diverse cultural backgrounds in universities?

- To what extent does the instrumentality cognition of lecturers influence their motivation to apply CRPs in the teaching of students of diverse cultural backgrounds in universities?

\section{Literature review}

\subsection{Understanding culture}

Various studies allude to the important role of culture in student learning and social adjustment in universities, hence the need for lecturers in universities to 
use CRPs to teach culturally diverse students. Hitchcock (2009, p.2) defines culture as "the shared learned meanings and behaviours derived from living within a particular life activity". Culture therefore "encompasses various aspects that include customs and values, traditions, communication, attitudes, beliefs, learning styles, rituals, behaviours and language that different cultural groups give priority to and that have a direct impact on teaching and learning" (Maasum et al., 2014, p.19). Adding to the above definitions, Dorrington and Guy (2018, p.9) define culture as "a combination of thoughts, feelings, attitudes, behaviour patterns and practices that are shared by social groupings". In the context of lecturers in universities therefore it is necessary for them to have adequate knowledge of the different cultures in the classrooms in order to be able to provide learning experiences that are both meaningful and engaging to students. Maasum et al. (2014) argue therefore that culture affects students' learning motivation, gender socialization, aspiration, task performance, as well as ways of interaction in the classroom. In the context of schools therefore culture encompasses broad notions, similarities and differences in the learning needs of students that are reflected in the students' multiple social identities and ways of knowing and viewing the world (Howe et al., 2021).

\subsection{The history and concept of culturally responsive pedagogies}

The history of CRPs can be traced back to the 1970s when a need arose for the development of an instructional strategy that caters for the multicultural educational needs of students (Forbes, 1973; Lardson-Billing, 1995). The need for multicultural education was meant to stimulate educators to come up with teaching strategies that accepted and affirmed the pluralism that students, their communities and teachers reflect (Dorrington \& Guy, 2018; Hutchison \& McAlister-Shields, 2020; Richardson, 2018). CRPs thus emerged as important teaching approaches that ensure inclusivity using culture as a cognitive scaffold (Norman, 2020; Cho, 2017; Kahu \& Nelson, 2018; Acquah \& Sezlei, 2020). A number of definitions have been used to enhance our understanding of CRPs. Gay (2018) defined CRPs as teaching approaches that draw on the cultural backgrounds and knowledge of students as assets in the classrooms. These cultural resources are used during the application of CRPs to "construct curriculum and pedagogic practices that promote learning within the context of and mediated by culture" (Wrench \& Garrett, 2020, p.7). According to studies by Morrison et al. (2019) and Warren (2018), this means that CRPs signpost approaches to teaching and learning that draw on the cultural resources of students to enhance learning as well as reducing learning gaps among students from diverse cultures. In their study, Howe et al. (2021) also found that the application of CRPs in universities addresses issues of student achievement and cultural identity while at the same time providing the means to deal with inequality in schooling.

The use of CRPs has long been associated with several positive academic outcomes for students that include improved academic performance, attitudes towards schooling and sense of self-awareness (Brown et al., 2018; Dreyfus, 2019; Gay, 2018). Effective implementation of CRPs therefore requires lecturers in universities who demonstrate multicultural competence (Norman, 2020; Lawrence, 2020). Lecturers who are multiculturally aware have (i) a full and 
clear understanding of their students' diverse cultures, (ii) knowledge of what each of the cultures considers learning, knowledge and how to learn, and (iii) the ability to design and implement teaching strategies that ensure learning experiences are not only relevant but also effective for each of the students (Brown et al., 2018; Richardson, 2018; Paris, 2012).

Separate studies by Dorrington and Guy (2018) and Tarasawa (2018) found that lecturer responsiveness during the use of CRPs when teaching culturally diverse students is evidenced through the lecturers' willingness to listen to and learn from all culturally diverse students. Such learning could be from what students talk about, bring to the classroom, and demonstrate in the classroom. Another study by Dreyfus (2019) found that CRPs engage students in culturally mediated learning and meaning making. Other studies by Hsiao (2015), Weaven and Clifford (2015) and Brockenbrough (2016) found that CRPs make learning contribute positively to meaning construction during the learning process because students mine their learning experiences from within their cultural backgrounds. A study by Cavendish et al. (2017) also found that lecturers who engage their students through the use of CRPs contribute to improved student attendance and completion rates, students' feelings of belonging and responsibility, as well as improved student disciplinary records.

\section{Theoretical and conceptual framework informing hypotheses formulation}

This study was informed by the EVT which is a theoretical framework developed by Victor Vroom (1964) and based on cognition and thought processes that deal with how individuals engage in conscious decision making to explain the motivation to behave in certain ways (Gemeda \& Tynjala, 2015; Bond \& Bedenlier, 2019; Gopalan et al., 2020). This theory helps us to understand how and why individuals continuously make evaluations of the outcomes of their actions or behaviours and subjectively assess the likelihood that each of their possible actions can lead to a multiplicity of outcomes (Chen et al., 2012; De Simone, 2015; Bond \& Bedenlier, 2019). In other words, the EVT argues that people will be motivated to behave in a certain way or perform at a certain level if they believe that a substantial effort effort will result in good performance and good performance will lead to desired rewards. In the context of the current study, the model shows that lecturers in universities should be motivated to apply CRPs when teaching culturally diverse students in universities if "they believe that use of CRPs will lead to effective teaching that will eventually result in improved performance by their students" (De Simone, 2015, p3). In a nutshell, the EVT helps us to understand why people select certain behaviours over the others based on an expectation of achieving the desired results. Studies by Gopalan et al. (2020) and Redmond (2015) found that the degree of motivation and effort that individuals put into their behaviour depends on three perceptual relationships or dimensions, namely expectancy (E), instrumentality (I) and valence $(\mathrm{V})$. The interaction among these three key elements of the EVT is summarised in the algebraic equation: Motivation $=E x I x V$.

The above relationship therefore shows that all the three dimensions of the EVT need to be present for lecturers in universities to be motivated to apply CRPs 
when teaching. This relationship implies that lecturers in universities can be motivated to use CRPs in their teaching of culturally heterogeneous students if they believe that they have the resources and the perceived control to be able to use CRPs. After the initial assessment, the lecturers will then assess whether their teaching performance using CRPs will lead to their obtaining positive outcomes, eventually to being rewarded and whether those rewards will meet their expectations. Based on the theoretical framework and literature review, a research model (Figure 1) was developed for the current study.

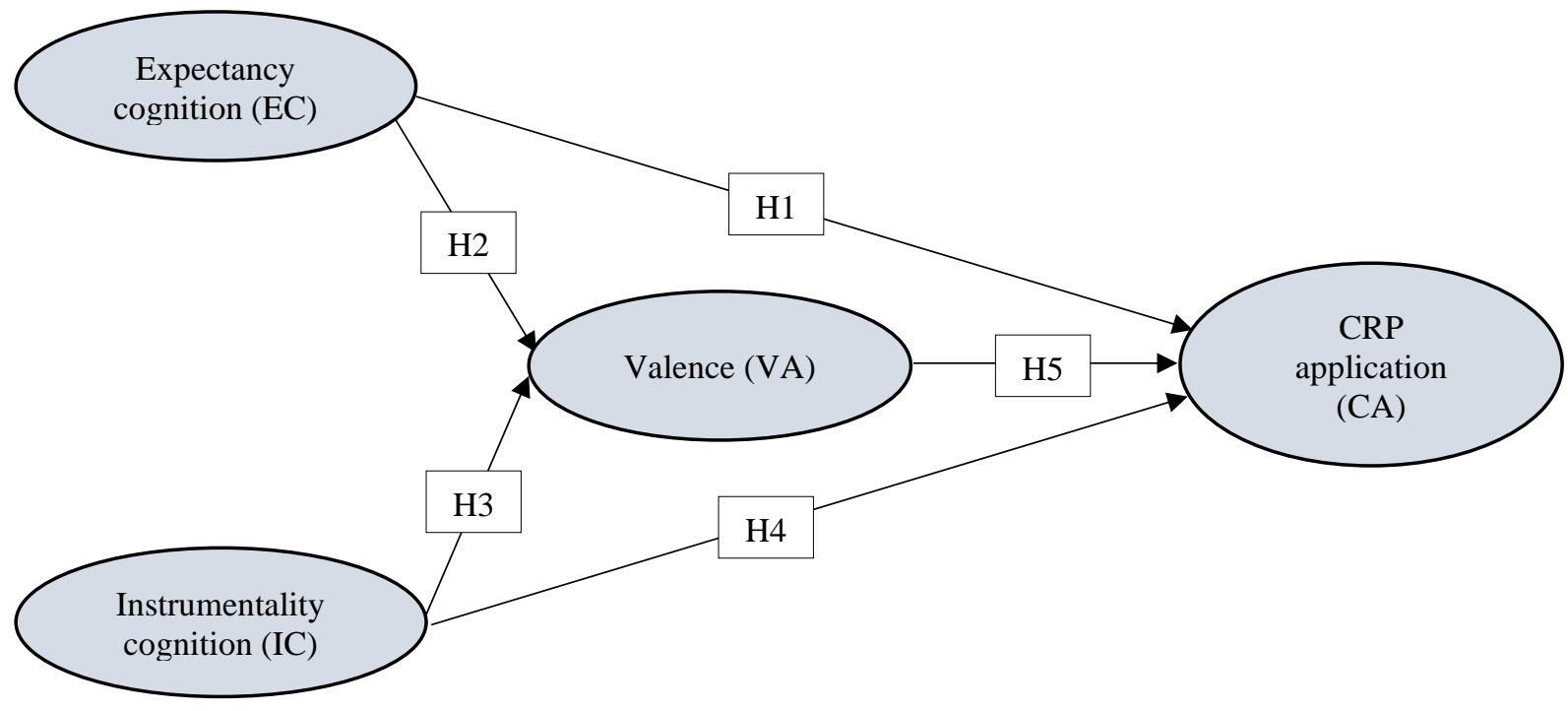

Figure 1: Research model for the application of CRPs

\subsection{Expectancy cognition}

Expectancy cognition is defined as "an individual's estimate of the probability that job-related effort will result in a given level of performance" (Gopalan et al., 2020, p.1). If a person estimates that there will not be any chance that his or her effort will result in a certain or expected level of performance, then the motivation to perform the task will be zero and vice versa (Redmond, 2015; De Simone, 2015; Penk \& Schipolowski, 2015). Expectancy cognition therefore is a subjective evaluation of the degree of effort actually related to the expected performance (Bond \& Bedenlier, 2019; Gemeda \& Tynjala, 2015). Studies by Thompson (2020) and De Simone (2015) found that the expectancy cognition of a person is influenced by factors that include confidence, self-efficacy, support from colleagues, the availability of information about the activities to be done, and the availability of resources. In the context of the current study, lecturers' estimation of the probability of successfully teaching culturally diverse students using CRPs will either motivate them to apply CRPs for teaching or not.

If lecturers believe that the effort they put into applying CRPs for teaching culturally diverse students will lead to the lecturers' improved performance levels (expectancy cognition) when teaching culturally diverse students, the lecturers will be motivated to apply CRPs in their teaching (Redmond, 2015). A study by Chen et al. (2012) also found a significant relationship between the amount of effort an individual is willing to expend and the level of performance 
that they expect to result from the effort. With reference to the current study, lecturers in universities can therefore be motivated to expend more effort in applying CRPs to teach culturally diverse students if they believe the necessary personal and external conditions allow them to perform their work to expected levels of performance. Also, a study by Fagbohungbe (2012) found that there was a significant relationship between valence and expectancy cognition. The above therefore means that once lecturers in universities feel that the effort they put in the application of CRPs in the teaching of culturally heterogeneous students can lead to their teaching better and being well rewarded, they will be motivated to teach using CRPs.

H1: The expectancy cognition of lecturers significantly influences their motivation to apply CRPs in the teaching of students of diverse cultural backgrounds in universities.

H2: The expectancy cognition of lecturers significantly influences valence in the teaching of students of diverse cultural backgrounds in universities.

\subsection{Instrumentality cognition}

The instrumentality cognition is defined as "an individual's estimate of the probability that a certain level of performance will result in a certain quality of outcome" (De Simone, 2015, p.5). It is also defined as "an individual's judgement of the probability that a given level of achieved task performance will lead to various work outcomes" (Penk \& Schipolowski, 2015, p.1). In summary, the instrumentality cognition of an individual therefore is the belief that if he or she meets certain performance expectations, then valuable rewards will follow (Gemeda \& Tynjala, 2015).

In light of the above definitions of instrumentality cognition, it can be inferred that if lecturers in universities realise that the use of CRPs to teach culturally diverse students will produce positive outcomes, the lecturers will almost always be motivated to apply the CRPs. A study by Lawler et al. (2009) found significant relationships between performance and outcomes and also between outcomes and valence. Their study (Lawler et al., 2009) further found that the reward of a positive outcome is only significant if individuals view the rewarding process as being transparent, have trust in the reward givers, and have an understanding of the rewarding system (criteria for rewarding). A study by Gemeda and Tynjala (2015) also found that the quality of a performance (instrumentality) has a significant influence on the quality of a reward (valence).

H3: The instrumentality cognition of lecturers significantly influences valence in the application of CRPs to teach students of diverse cultural backgrounds in universities.

H4: The instrumentality cognition of lecturers significantly influences their motivation to apply CRPs to teach students of diverse cultural backgrounds in universities.

\subsection{Valence}

Valence relates to the value an individual attaches to a reward of an outcome based on needs, goals, values, and sources of motivation (Redmond, 2010). This suggests that valence is the perceived value lecturers assign to the outcomes of their effort after applying CRPs to teach culturally diverse university students. Tinsley (2016) defines valence as the value or desirability of the expected outcome of an effort while Ernst (2014) defines it as the degree of strength of a person's attraction to an outcome. This also suggests that for valence to be 
viewed as positive or valuable, the lecturer would have attained, for example, improved academic performance of students as an outcome of using CRPs. Lecturers who therefore believe that teaching students using CRPs will result in effective teaching which will lead to their being recognized or promoted will be motivated to apply CRPs every time when teaching culturally diverse students.

A study by Tinsley (2016) found that there is a significant relationship between the value individuals assign to the reward of what is achieved and the quality of the outcome. This means that if lecturers believe that the reward given matches the outcome achieved as a result of the use of CRPs to teach students, the lecturers will value the reward more as they will feel that they have earned it and will be motivated to always use CRPs when teaching culturally diverse students.

H3: Valence significantly influences the motivation of lecturers in universities to apply CRPs in the teaching of students of diverse cultural backgrounds in universities.

\section{Materials and methods}

\subsection{Research design and sampling}

A descriptive research design that employed a structured questionnaire to collect data on the use of CRPs by university lecturers was employed in the study. In addition, a stratified random sampling approach was used to select a sample of 291 lecturers from a lecturer population of 1209 from three universities. The study used the sample size table developed by the Research Advisors (2006) at a 95\% confidence level and a 5\% margin of error to determine the sample size for this study. The individual sample sizes for each of the three universities were as follows: $\mathrm{U} 1=90, \mathrm{U} 2=107$ and U3 $=94$ lecturers. For data collection procedures, 291 questionnaires were administered through handdelivery to the lecturers (since this was during the pre-COVID-19 lockdown period). Offices of Deans of Faculties were used to facilitate the administration of the questionnaires to the selected lecturers in each of the universities. A total 169 completed questionnaires were returned, giving a rate of return of $58.1 \%$ which was considered adequate enough to produce reliable results. Demographic profiles of respondents are shown in Table 1.

Table 1: Analysis of lecturer demographic factors

\begin{tabular}{lcc}
\hline Factors & Item & $\%$ \\
\hline Age & $\leq 30$ years & 15 \\
& $31-40$ years & 47 \\
& $41^{+}$years & 38 \\
Gender & Male & 61 \\
& Female & 39 \\
Educational level & Master's & 53 \\
& Doctoral & 41 \\
Teaching experience & Other & 6 \\
& $\leq 5$ years & 21 \\
& $10-20$ years & 43 \\
& $21^{+}$years & 36 \\
\hline
\end{tabular}

http://ijlter.org/index.php/ijlter 
The results in Table 1 show that most of the lecturers (62\%) were 40 years old and younger, indicating that universities in Botswana are now populated by a relatively young group of lecturers. There are still gender imbalances in the Botswanan university teaching staff as most of the lecturers $(61 \%)$ are male. The majority of the lecturers (53\%) have a master's degree. Furthermore, most of the lecturers $(64 \%)$ have 20 years or less of teaching experience which resonates with the fact that most of the lecturers are 40 years old or younger.

\subsection{Instrument development}

A self-constructed structured questionnaire with four sections was used for data collection in the study. This questionnaire was developed by the researchers based on the reviewed literature and the theoretical framework. The 30-item questionnaire comprised the following four sections and items: Expectancy cognition (EC) - 11 items, instrumentality cognition (IC) - 8 items, valence (VA) - 6 items, and lecturer motivation to apply CRPs (CA) - 5 items. The questionnaire used a five-point Likert scale ranging from Strongly agree (SA-5), Agree (A-4) and Neutral (N-3) to Disagree (DA-2) and Strongly disagree (SDA$1)$.

\section{Results}

The Software Package for Social Sciences (SPSS) version 24 was used for data analysis. For data cleansing confirmatory factor analysis (CFA) was used. Structural equation modelling (SEM) that uses AMOS version 22 was used to test the relationship among the three predictor variables, namely EC, IC and VA and the criterion variable CA. In the second test, the SEM was used to establish the relationship between the two predictor variables, namely EC and IC and the criterion variable VA.

\subsection{Measurement model assessment}

The researchers validated the data using multiple tools that included a measurement of internal consistency reliability, content validity, construct validity, convergent validity, discriminant validity and a structural model. For the measurement of internal consistency reliability, the researchers used the Cronbach's alpha of each construct. The results in Table 2 show that for each construct, the a values ranged between .729 and .835 while the $C R$ values ranged between .833 and .915 , thereby satisfying the minimum requirement of CR $>.06$ for internal consistency reliability (Kawakami et al., 2020; Gravesande et al., 2019), hence demonstrating the presence of adequate internal consistency reliability in the data. Content validity in the study was assured through a rigorous literature review relating to all three constructs (Pallant, 2016). The construct validity and discriminant validity were assessed using CFA (Table 2). All $\lambda$ values range between .704 and .869 (Table 2), thereby satisfying the minimum requirement for construct validity of $\lambda>.06$ (Bagozzi \& Yi, 1988), hence confirming the presence of adequate construct validity. Also, to measure convergent validity, values of $\lambda, C R$ and AVE were used. The results in Table 2 also show that all the values of $\lambda>.6$, all the values of $C R>.6$ and the values of AVE $>.6$ satisfy the minimum requirements for convergent validity, hence demonstrating the presence of adequate convergent validity. 
Table 2: Confirmatory factor analysis results ( $\lambda$, CR and AVE)

\begin{tabular}{|c|c|c|c|c|c|}
\hline $\begin{array}{l}\text { Model } \\
\text { Constructs }\end{array}$ & Construct Items & 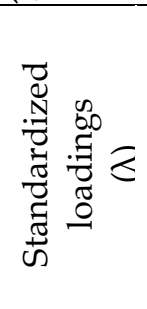 & 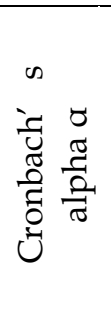 & 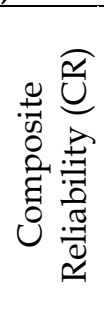 & 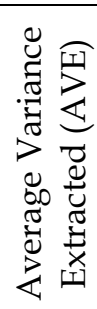 \\
\hline EC & $\begin{array}{l}\text { EC2: I find the performance of my students } \\
\text { improves when teaching them using CRPs. } \\
\text { EC3: I am always provided with adequate } \\
\text { and appropriate teaching resources to } \\
\text { apply CRPs. } \\
\text { EC5: My level of motivation is always high } \\
\text { when applying CRPs. } \\
\text { EC6: The support I get from my peers } \\
\text { always helps me to improve my } \\
\text { application of CRPs. } \\
\text { EC7: My knowledge of the different } \\
\text { cultures in my class helps me to improve } \\
\text { how I apply CRPs effectively when } \\
\text { teaching culturally diverse students. } \\
\text { EC8: I always demonstrate a high sense of } \\
\text { self-efficacy when applying CRPs to teach } \\
\text { culturally diverse students. } \\
\text { EC10: I am always eager to apply CRPs to } \\
\text { improve the performance of my culturally } \\
\text { diverse students. }\end{array}$ & .744 & .781 & .860 & .611 \\
\hline \multirow[t]{5}{*}{ IC } & $\begin{array}{l}\text { IC1: My performance in the application of } \\
\text { CRPs always helps me to achieve better } \\
\text { results when teaching culturally diverse } \\
\text { students. }\end{array}$ & .747 & .729 & .833 & .647 \\
\hline & $\begin{array}{l}\text { IC3: Achieving positive outcomes when } \\
\text { applying CRPs means a lot to me. }\end{array}$ & .704 & & & \\
\hline & $\begin{array}{l}\text { IC4: I am always able to make a good } \\
\text { judgement of whether my application of } \\
\text { CRPs will lead to positive student } \\
\text { outcomes. }\end{array}$ & .761 & & & \\
\hline & $\begin{array}{l}\text { IC5: I would rather not use CRPs to teach } \\
\text { culturally diverse students because the } \\
\text { outcomes I obtain in terms of student } \\
\text { performance do not always match the } \\
\text { quality of my teaching performance. }\end{array}$ & .762 & & & \\
\hline & $\begin{array}{l}\text { IC6: Teaching culturally diverse students } \\
\text { using CRPs is very personally satisfying } \\
\text { with regard to the quality of outcomes I } \\
\text { always achieve. }\end{array}$ & .741 & & & \\
\hline \multirow[t]{2}{*}{ VA } & $\begin{array}{l}\text { VA1: The rewards I obtain after } \\
\text { successfully applying CRPs to teach } \\
\text { culturally diverse students mean a lot to } \\
\text { me. }\end{array}$ & .869 & .835 & .915 & .602 \\
\hline & $\begin{array}{l}\text { VA3: I feel adequately rewarded when I } \\
\text { successfully use CRP }\end{array}$ & .815 & & & \\
\hline
\end{tabular}


VA4: I always want to see that the

outcomes of my teaching performance

using CRPs lead to a satisfying reward

VA6: I find rewards I obtain after

successfully using CRPs to teach culturally

.791

diverse students to be important in

motivating me to always apply CRPs in my

teaching.

CA

CA1: Using CRPs to teach students of

thing to do.

CA3: Using CRPs to teach students of

different cultural backgrounds is a very

tiring process.

CA4: Using CRPs to teach students of

different cultural backgrounds requires a

great deal of preparation.

CA6: I received training on the use of CRPs

to teach students of different cultural

backgrounds.

A test of discriminant validity of scale items is shown in Table 3. AVE values (bold diagonal values) and inter-construct correlations were compared to demonstrate the discriminant validity of scale items. The results of the study show that the AVE values for each of the constructs were higher than the vertical correlations of the variables (inter-construct correlations), thereby confirming the presence of discriminant validity (Hair et al., 2017).

Table 3: Measurement of discriminant validity

\begin{tabular}{lllll}
\hline Constructs & CA & EC & IC & VA \\
\hline Motivation to apply CRPs (CA) & .681 & & & \\
Expectancy cognition (EC) & $.433^{* *}$ & .647 & & \\
Instrumentality cognition (IC) & $.391^{* *}$ & $.213^{* *}$ & .602 & \\
Valence (VA) & $.304^{* *}$ & $.248^{* *}$ & $.382^{*}$ & .614 \\
\hline
\end{tabular}

${ }^{*}$ Sig. $p<.05$ (two-tailed), ${ }^{*}$ Sig. $p<.01$ (two-tailed)

Bold diagonal values represent values of AVE for each construct

\subsection{Structural model assessment}

Researchers employed a SEM approach using AMOS version 22 to evaluate the structural properties of the model.

The goodness-of-fit metrics that were used for the evaluation were the following: CMIN/degrees of freedom $(x 2 / \mathrm{df})$, goodness of fit index (GFI), adjusted goodness-of-fit index (AGFI), normed fit index (NFI), Tucker-Lewis index (TLI), comparative fit index (CFI), and the root mean square error of approximation (RMSEA) (Kline, 2005; Hooper et al., 2008; Hu \& Bentler, 1999; Byrne, 1998) (Table 4). The results in Table 4 show that the modified measurement assessment indices satisfied the minimum requirements for model fit, thereby demonstrating overall model fit ( $\mathrm{Hu} \&$ Bentler, 1999; Kline, 2005; Reisinger \& Mavondo, 2007). 
Table 4: Measurement model assessment using model fit indices;

\begin{tabular}{|c|c|c|c|c|c|}
\hline $\begin{array}{ll}\text { Model fit } \\
\text { measures }\end{array}$ & $\begin{array}{l}\text { Model } \\
\text { fit } \\
\text { indices }\end{array}$ & $\begin{array}{l}\text { Initial } \\
\text { measurement } \\
\text { model }\end{array}$ & $\begin{array}{l}\text { Modified } \\
\text { measurement } \\
\text { model }\end{array}$ & $\begin{array}{l}\text { Recommended } \\
\text { values }\end{array}$ & Sources \\
\hline \multirow[t]{3}{*}{$\begin{array}{ll}\text { Absolute fit } \\
\text { measures }\end{array}$} & $x^{2 / d f}$ & 1.725 & 1.933 & $\leq 3.000$ & $\begin{array}{l}\text { Hu and Bentler } \\
\text { (1999); Reisinger } \\
\text { and Mavondo } \\
\text { (2007) }\end{array}$ \\
\hline & GFI & .865 & .971 & $\geq .950$ & $\begin{array}{l}\text { Hu and Bentler } \\
\text { (1999); Reisinger } \\
\text { and Mavondo } \\
\text { (2007) }\end{array}$ \\
\hline & AGFI & .850 & .943 & $\geq .900$ & $\begin{array}{l}\text { Hu and Bentler } \\
\text { (1999); Reisinger } \\
\text { and Mavondo } \\
\text { (2007) }\end{array}$ \\
\hline \multirow[t]{2}{*}{$\begin{array}{l}\text { Incremental } \\
\text { fit measures }\end{array}$} & NFI & .961 & .979 & $\geq .950$ & $\begin{array}{l}\text { Hu and Bentler } \\
\text { (1999); Reisinger } \\
\text { and Mavondo } \\
\text { (2007) }\end{array}$ \\
\hline & TLI & .958 & .980 & $\geq .950$ & $\begin{array}{l}\text { Reisinger and } \\
\text { Mavondo (2007); } \\
\text { Hu and Bentler } \\
\text { (1999); Kline } \\
\text { (2005) }\end{array}$ \\
\hline \multirow[t]{2}{*}{$\begin{array}{l}\text { Parsimonious } \\
\text { fit measures }\end{array}$} & CFI & .916 & .930 & $\geq .900$ & $\begin{array}{l}\text { Reisinger and } \\
\text { Mavondo (2007); } \\
\text { Hu and Bentler } \\
\text { (1999); Kline } \\
\text { (2005) }\end{array}$ \\
\hline & RMSEA & .0425 & .0472 & $<.080$ & $\begin{array}{l}\text { Hu and Bentler } \\
\text { (1999); Reisinger } \\
\text { and Mavondo } \\
\text { (2007) }\end{array}$ \\
\hline
\end{tabular}

\subsection{Hypotheses testing}

The relationships between predictor variables, namely expectancy cognition (EC), instrumentality cognition (IC) and valence (VA) and the dependent variable, namely lecturer motivation to apply CRPs (CA) was assessed. The relationship between expectancy cognition and valence as well as between instrumentality cognition and valence was also tested.

The results in Table 5 and in the path coefficient diagram (Figure 2) show that the hypothesised relationships between expectancy cognition and lecturer motivation to apply CRPs (H1), expectancy cognition and valence (H2), instrumentality cognition and valence $(\mathrm{H} 3)$ were all supported. The results further show that the hypothesized relationship between the instrumentality cognition and lecturer motivation to application of CRPs (H4) as well as the relationship between valence of rewards associated with the application of CRPs and lecturer motivation to apply CRPs (H5) were also supported. 
The results in Table 5 show the explanatory power of the latent variables as follows: $\mathrm{EC}(51 \%), \mathrm{IC}(44 \%), \mathrm{VA}(37 \%)$, and CA (69\%), with EC explaining the highest variance and VA the lowest variance on the CA of lecturers to apply CRPs. The model as a whole explains $69 \%$ of the variance in application of CRPs in universities.

Table 5: Test of hypotheses (H1-H5)

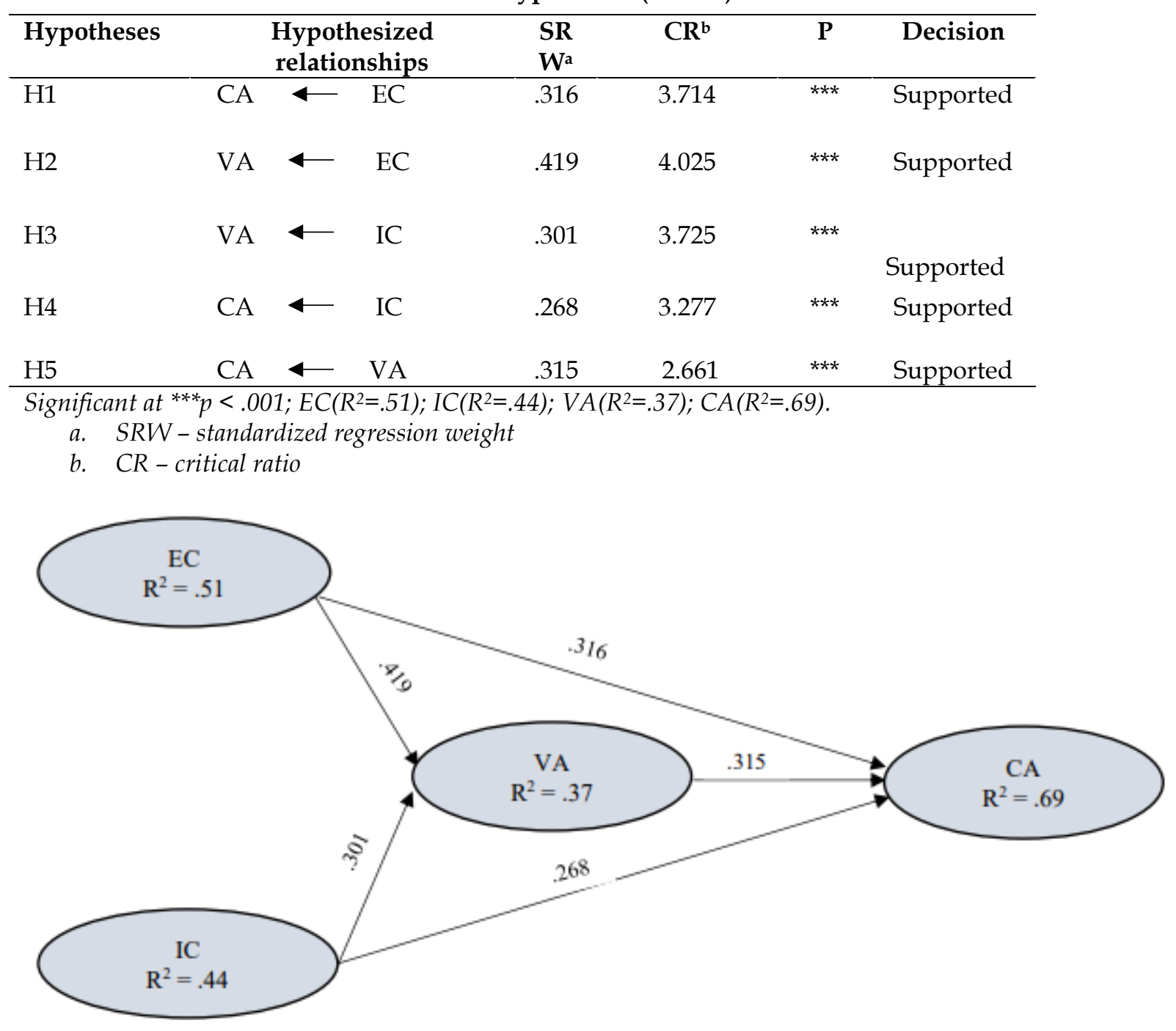

Figure 2: Path coefficient of the research

\section{Discussion}

The main goal of the study was to determine whether the expectancy value theory (EVT) could be used to predict and explain the motivation by lecturers in universities to apply CRPs. The theory argues that the motivation of individuals to think and behave in a certain way is motivated and mediated by three key dimensions of the EVT, namely expectancy cognition, instrumentality cognition, and valence. These were used to demonstrate the efficacy of the EVT to predict and explain the lecturers in universities' motivation to apply CRPs. 
It was shown in the study that the expectancy cognition of lecturers significantly influenced the motivation of lecturers in universities to use CRPs to teach students of diverse cultural backgrounds. These results suggest that if lecturers believe that if they put more effort in the application of CRPs in the teaching of students of diverse cultural backgrounds, they will achieve positive outcomes (expectancy cognition), then such lecturers will apply CRPs every time they teach students of diverse cultural backgrounds in universities. Lecturers in universities therefore need to feel that effective teaching on their part will lead to higher levels of performance on the part of students from their efforts in applying CRPs for them to be motivated to do so. This confirms the findings of previous studies by Chen et al. (2012) and Redmond (2015) which found that there is a significant relationship between the amount of effort an individual is willing to expend and the level of performance expected to result from the effort.

It further emerged from the study that valence significantly influences the motivation of lecturers to apply CRPs during the teaching of culturally diverse university students. These results suggest that the quality of rewards that lecturers expect to achieve after successfully applying CRPs is a critical predictor of their level of motivation to apply CRPs when teaching culturally diverse students in universities. These results confirm the findings of earlier studies that found that there was a significant relationship between valence and performance of a task. A study by Chang (2005) found that if a reward meets the needs of the individual, that is, if it is of significant value to an individual, based on the outcome achieved, that reward will lead to motivation to either continue with the good performance or to perform better in future. In the context of the current study, if a lecturer is promoted, for example, after successfully using CRPs to improve the academic performance of culturally diverse students, such a lecturer would be motivated to continue using the CRPs when teaching such students.

The study also found that the instrumentality cognition of lecturers significantly influenced their motivation to apply CRPs in teaching students of diverse cultural backgrounds in universities. These results suggest that lecturers who believe that if they use CRPs they will achieve an outcome which will result in a reward, will be motivated to apply CRPs every time in their teaching of students of diverse cultural backgrounds. In the context of the current study, if lecturers feel that the application of CRPs will enable them to effectively teach their students which in turn will lead to positive outcomes and eventually to getting rewards such as promotion or other forms of recognition that meet their expectations, those lecturers will be motivated to use CRPs to teach their students. These results confirm findings of earlier studies. A study by De Simone (2015) found that an individual who believes that a good performance will lead to positive outcomes, resulting in being rewarded, is always motivated to demonstrate that level of performance. In the context of this study, lecturers will always demonstrate motivation to apply CRPs in their teaching if they believe that the successful application of CRPs will lead to positive outcomes such as high academic performance by students. 
Finally, it also emerged from this study that the both expectancy and instrumentality cognitions of lecturers have a significant influence on how lecturers assign value (valence) to the rewards they achieve after successfully applying CRPs in their teaching. This suggests that expectations of positive performance levels (expectancy cognition) by both lecturers and students as well as expectations of positive outcomes (instrumentality cognition) such as rewards by lecturers after using CRPs to teach students of diverse cultural backgrounds determine how much value the lecturers assign to the rewards they receive after successfully applying CRPs. This further suggests that when lecturers put a great deal of effort into applying CRPs, they expect to achieve high levels of performance and also receive meaningful rewards that match the performance otherwise they will not be motivated to apply CRPs in future These results confirm the findings of past studies. A study by Fagbohungbe (2012) found that there is a significant relationship between valence and both expectancy and instrumentality cognitions of lecturers. Another study by Madaus and Russell (2010) found that once individuals feel that they are likely to perform at higher levels and also expect to get rewards of value (valence) for their efforts, they are likely to engage in that behaviour. A study by De Simone (2015) also found that if individuals believe that a good performance will result in positive rewards, they will always be motivated to demonstrate that level of performance.

\section{Conclusions}

The study was meant to determine whether the EVT could be used to predict and explain the motivation of lecturers in universities to apply CRPs when teaching students of diverse cultural backgrounds. Based on the results of the study, it was observed that expectancy cognition, instrumentality cognition and valence significantly influenced the motivation of lecturers in universities to apply CRPs when teaching students of diverse cultural backgrounds. It was also observed that expectancy cognition as well as the instrumentality cognition of lecturers influenced the valence. Based on these observations, it was therefore concluded that that the EVT could be used to predict and explain the motivation of lecturers in universities to apply CRPs when teaching students of diverse cultural backgrounds. It was also concluded that the quality of rewards which lecturers receive after successfully using CRPs to teach culturally diverse students was important as a motivational factor in their application of CRPs by lecturers in universities.

\section{Recommendations}

Based on the above conclusions, a number of recommendations were suggested to motivate lecturers in universities to apply CRPs when teaching students of diverse cultural backgrounds. First, universities need to ensure that adequate and appropriate resources are available for the lecturers to feel that they can achieve positive results when teaching using CRPs. Such resources could include the availability of relevant textbooks, technology and support. Second, periodic training of lecturers to re-skill or upskill them with modern CRP strategies is also important for lecturers to continue having high levels of motivation to apply CRPs when teaching culturally diverse students. Third, rewards that lecturers receive after successfully implementing CRPs when teaching culturally diverse students should always meet the expectations of the lecturers if they are 
to remain motivated to apply CRPs when teaching students of diverse cultural backgrounds. Finally, universities need to come up with policy guidelines on the use of CRPs in teaching university students whose populations have become highly heterogeneous in terms of cultural backgrounds.

\section{Practical implications of the study}

Results of this study underwrite the critical importance of motivating lecturers in universities to always apply CRPs when teaching students of diverse cultural backgrounds. Motivated lecturers will go a long way in ensuring that the learning needs of students from diverse cultures are catered for, hence ensuring that students perform better academically. These results also have implications for theory with regard to the contribution of the study to the body of knowledge on CRPs as well as for policy in terms of advocating for policy guidelines in universities on the teaching of students of diverse cultural backgrounds.

\section{Limitations of the study}

The study only used public universities in Botswana. Since there are currently around 10 universities in Botswana (public and private), the study may have perhaps mined more data if all these universities were used in the study. Future studies therefore could also seek to hear the voice of private universities with regard to the motivation of their lecturers to apply CRPs when teaching students of diverse cultural backgrounds.

\section{Declarations}

Informed consent: Informed consent was obtained from all participants before the start of the study.

Ethics approval and consent to participate: The researchers were given permission by their respective university research ethics boards to conduct the study.

Availability of data and materials: There are no data issues to declare in this study.

Conflicting interests: The authors declare no conflicting issues or interests in this study.

Funding: The study has no funding issues or interests to declare.

Methods: All research methods used in this study were in accordance with relevant research guidelines and regulations for conducting ethical research.

Acknowledgement: The researchers wish to thank all lecturers who participated in this study.

\section{References}

Bond, M., \& Bedenlier, S. (2019). Facilitating student engagement through educational technology: Towards a conceptual framework. Journal of Interactive Media in Education, 1(11), 1-14.

Brockenbrough, E. (2016). Becoming queerly responsive: Culturally responsive pedagogy for black and Latino urban queer youth. Urban Journal, 51(2), 170-196.

Brown, J. C., \& Crippen, K. J. (2017). The knowledge and practices of high school science teachers in pursuit of cultural responsiveness. Science Education, 101(1), 99-133.

Brown, J., Ring-Whalen, E. A., Roehrig, G., \& Allis, J. A. (2018). Advancing culturally responsive science education in secondary classrooms through an induction course. International Journal of Designs for Learning, 9(1),14-33. 
Brown, K. D. (2014). Teaching in color: A critical race theory in education analysis of the literature on preservice teachers of colour and teacher education in the US. Race Ethnicity and Education, 17(3), 326-345.

Byrne, B. M. (1998). Structural equation modelling with Lisrel, Prelis and Simplis: Basic concepts, applications and programming. Lawrence Erlbaum Associates.

Cavendish, W., Marquez, A., Roberts, M., Suarez, K., \& Lima, W. (2017). Student engagement in high-stakes accountability systems: Perspectives on urban education. www.urbanedjournal.org

Chang, S. E. (2005). Computer anxiety and perception of task complexity in learning programming-related skills. Computers in Human Behaviour, 21(5), 713-728.

Chen, Y., Little Jr., H. T., Ross, M. T., \& Zhao, Q. (2012). Factors motivating the adoption of e- learning technologies. Journal of e-Learning \& Higher Education, 12, 1-17.

De Simone, S. (2015). Expectancy value theory: Motivating healthcare workers. American International Journal of Contemporary Research, 5(2), 19-23.

Diaz, J., Suarez, C., \& Valencia, L. (2019). Culturally responsive teaching: A framework for educating diverse audiences. University of Florida: IFAS Extension.

Diller, J. V., \& Moule, J. (2005). Cultural competence: A primer for educators. Thomson Wadsworth.

Dorrington, A. E. L., \& Guy, L. (2018). It's not "just" good teaching: Cultural responsive teaching for educators. National Education Student Program Webinar.

Dreyfus, W. 2019. Teacher perceptions of culturally responsive pedagogy in the classroom [Doctoral thesis, Graduate School of Education, Northeastern University, Boston, MA].

Ernst, D. (2014). Expectancy theory outcomes and student evaluations of teaching. Educational Research and Evaluation, 20(7-8), 536-556.

Fagbohungbe, B. (2012). Students' performance in core and service courses: A test of valence instrumentality expectancy theory. Journal of Management and Sustainability, 2(3), 236-240.

Gay, G. (2018). Culturally responsive teaching. Theory, research, and practice. Teachers College Press.

Gemeda, F. T., \& Tynjälä, P. (2015). Exploring teachers' motivation for teaching and professional development in Ethiopia: Voices from the field. Journal of Studies in Education, 5(2), 169-186.

Gopalan, V., Bakar, J. A. A., \& Zulkifli, A. N. (2020). A review of motivation theories, models and instruments in learning environment. Journal of Critical Reviews, 7(6), 554-559.

Gravesande, J., Richardson, J., Griffith, L., \& Scott, F. (2019). Test-retest reliability, internal consistency, construct validity and factor structure of a falls risk perception questionnaire in older adults with type 2 diabetes mellitus: A prospective cohort study. Archives of Physiotherapy, 9(14), 1-11. https:// doi.org/10.1186/s40945-019-0065-4

Hair, J. F., Hult, G. T. M., Ringle, C. M., \& Sarstedt, M. (2014). A primer on partial least squares structural equation modelling (PLS-SEM). Sage.

Hair, J. F., Hult, G. T. M., Ringle, C. M., \& Sarstedt, M. (2017). A primer on partial least squares structural equation modelling (PLS-SEM) (2nd ed.). Sage.

Hooper, D., Coughlan, J., \& Mullen, M. R. (2008). Structural equation modelling: Guidelines for determining model fit. The Electronic Journal of Business Research Methods, 6(1), 53-60. 
Howe, E., Musayett, S. J., \& Momo, S. T. (2021). Effective indigenization of curriculum in Canada and New Zealand: Towards culturally responsive pedagogies. Journal of Contemporary Issues in Education, 16(1), 23-39.

Howell, J., Kurlaender, M., \& Grodsky, E. (2010). Postsecondary preparation and remediation: Examining the effect of the early assessment program at California State University. Journal of Policy Analysis and Management, 29(4), 726-748.

Hsiao, Y. (2015). The culturally responsive teacher preparedness scale: An exploratory study. Contemporary Issues in Education Research, 8(4), 241-249.

Hu, L. T., \& Bentler, P. M. (1999). Cut-off criteria for fit indexes in covariance structure analysis: Conventional criteria versus new alternatives. Structural Equation Modeling, 6(1), 1-55.

Kawakami, N., Thi, T. T. T., Watanabe, K., Imamura, K., Thanh, N. H., Sasaki, N., ...Tsutsumi, A. (2020). Internal consistency reliability, construct validity, and item response characteristics of the Kessler 6 scale among hospital nurses in Vietnam. PLOS One, 15(5), 1-10. https:/ / doi.org/10.1371/journal.pone.0233119

Kline, R. B. (2005). Principles and practice of structural equation modeling ( $2 \mathrm{nd}$ ed.). The Guilford Press.

Lawler, E., Porter. L., \& Vroom, V. (2009). Motivation and management Vroom's expectancy theory.

http://www.valuebasedmanagement.net/methods_vroom_expectancy_theory. htmlhttp://www.valuebasedmanagement.net/methods_vroom_expectancy_the ory.html.

Lawrence, A. (2020). Teaching as dialogue: An emerging model of culturally responsive online pedagogy. Journal of Online Learning Research, 6(1), 5-33.

Maasum, T., Maarof, N., \& Ali, M. (2014). Addressing student diversity via culturally responsive pedagogy. Social and Behavioral Sciences, 134, 101-108.

Madaus, G., \& Russell, M. (2010). Paradoxes of high-stakes testing. Journal of Education, 190(1/2), 21-32.

Mathers, N., Fox, N., \& Hunn A. (2007). Surveys and questionnaires. NIHR RDS.

Morrison, A., Rigney, L. I., Hattam, R., \& Diplock, A. (2019). Toward and Australian culturally responsive pedagogy: A narrative review of the literature. University of South Australia.

Nagasawa, K. (2020). Culturally responsive pedagogy in mathematics. Iris Journal of Scholarship, 2, 145-158. https://doi.org/10.15695/iris.v2i0.4808.

Norman, T. R. (2020). Creating inclusive classrooms through culturally responsive pedagogy. Theses and Dissertations. 2759. https://rdw.rowan.edu/etd/2759

Pallant, J. (2016). SPSS survival manual. A step-by-step guide to data analysis using SPSS Program (6th ed.). McGraw-Hill Education.

Paris, D. (2012). Culturally sustaining pedagogy: A needed change in stance, terminology, and practice. Educational Researcher, 41(3), 93-97.

Penk, C., \& Schipolowski, S. (2015). Is it all about value? Bringing back the expectancy component of the assessment of test-taking motivation. Learning and Individual Differences, 42, 27-35.

Redmond, B. (2010). Lesson 4: Expectancy theory: Is there a link between my effort and what I want? https://cms.psu.edu

Redmond, B. F. (2015). Expectancy theory. https://psu.edu/viewpage/actions

Reisinger, Y., \& Mavondo, F. (2007). Structural equation modelling. Journal of Travel ETourism Marketing, 21(4), 41-71.

Richardson, C. (2018). Culturally responsive pedagogy in teacher education: Are we adequately preparing pre-service teachers to circumvent cultural marginality in the classroom? 
[Dissertation, Georgia State University]. https://scholarworks.gsu.edu/epse_diss/121

Tarasawa, B. (2018). Three research-based culturally responsive teaching strategies. https://www.nwea.org/blog/author/btarasawa/

The Research Advisors. (2006). The Morgan sample size table. http://researchadvisors.com/index.php

Thompson, S. C. (2020). Perceived control. https://cancercontrol.cancer.gov/brp/research/constructs/perceived-control

Tinsley, A. L. (2016). Fall 2011 case application - Expectancy theory. https:// wikispaces.psu.edu/display/PSYCH484001SP17/Fall+2011+Case+App lication-+Expectancy+Theory

Vroom, V. H. (1964). Work and motivation. Wiley.

Warren, C. A. (2018). Empathy, teacher dispositions and preparation for culturally responsive pedagogy. Journal of Teacher Education, 69(2), 169-183. https://doi.org/10.1177/0022487117712487

Weaven, M., \& Clifford, R. (2015). Creating cultural capital in the classroom: Being perfectly frank about writing. English in Australia, 50(2), 61-70.

Wrench, A., \& Garrett, R. (2020): Navigating culturally responsive pedagogy through an indigenous games unit. Sport, Education and Society, 1-13. https://doi.org/10.1080/13573322.2020.1764520 